\title{
Calendário floral de plantas melíferas nativas da Borda Oeste do Pantanal no Estado do Mato Grosso do Sul
}

\author{
Suzana Maria Salis(1), Edileuza Medeiros de Jesus ${ }^{(2)}$, Vanderlei Doniseti Acassio dos Reis ${ }^{(1)}$, \\ Ademir Marques de Almeida( ${ }^{(2)}$ e Daly Roxana Castro Padilha ${ }^{(3)}$
}

\begin{abstract}
(1)Embrapa Pantanal, Rua 21 de Setembro, no 1.880, Caixa Postal 109, CEP 79320-900 Corumbá, MS, Brasil. E-mail: suzana.salis@embrapa.br, vanderlei.reis@embrapa.br (2)Universidade Federal de Mato Grosso do Sul (UFMS), Campus do Pantanal, Avenida Rio Branco, no 1.270, CEP 79304-902 Corumbá, MS, Brasil. E-mail: edileuzadez@hotmail.com, adr-almeida@hotmail.com (3)UFMS, Campus de Chapadão do Sul, Rodovia MS 306, Km 105, Caixa Postal 112, CEP 79560-000 Chapadão do Sul, MS, Brasil. E-mail: daly.padilha@ufms.br
\end{abstract}

Resumo - O objetivo deste trabalho foi avaliar o padrão de floração, ao longo do ano, de plantas melíferas na Borda Oeste do Pantanal, no Maciço do Urucum, MS, bem como o tipo de recurso oferecido pela flora melífera, para elaborar um calendário floral para a região. A floração das plantas melíferas visitadas pelas abelhas nativas e africanizadas foi acompanhada quinzenalmente, por 3 anos consecutivos, tendo-se anotado a data de florescimento, o hábito de crescimento e os recursos coletados pelos insetos. Foram identificadas 160 espécies florescendo e sendo visitadas pelas abelhas, mas somente 73 espécies foram consideradas como plantas melíferas e incluídas no calendário floral, das quais 34 eram ervas, 17 árvores, 15 arbustos e 7 lianas. Foram observadas plantas melíferas em flor ao longo de todo o ano, com maior número no verão e menor no inverno. As ervas florescem mais intensamente no verão e no outono (janeiro-junho), enquanto as árvores e os arbustos, na primavera (final de setembro-dezembro). As lianas florescem, principalmente, no final do verão (março-abril). Néctar e pólen são oferecidos às abelhas ao longo de todo o ano, com diminuição da oferta nos meses de inverno (julho-setembro).

Termos para indexação: Apis mellifera, apicultura, época de floração, flora melífera, inventário botânico, meliponicultura.

\section{Floral calendar of honey plants native to the western Pantanal wetlands in the state of Mato Grosso do Sul, Brazil}

\begin{abstract}
The objective of this work was to evaluate the flowering pattern, throughout the year, of honey plants in the western region of the Pantanal, at the Urucum Massif, in the state of Mato Grosso do Sul, Brazil, as well as the type of resources offered by the honeybee flora, in order to create a floral calendar for the region. The flowering of honey plants visited by native and Africanized bees was monitored at 15 -day intervals, over 3 consecutive years, and records were taken of flowering date, growth habit, and the resources collected by the insects. A total of 160 flowering plant species visited by the bees were recorded, but only 73 species were considered as honey plants and included in the floral calendar, of which 34 were herbs, 17 trees, 15 shrubs, and 7 lianas. Flowering honey plants were observed throughout the year, with highest number in summer and lowest in winter. Herbs flower more intensely in summer and autumn (January-June), and trees and shrubs in spring (late September-December). Lianas flower mainly in late summer (March-April). Nectar and pollen are available for honeybees throughout the year, with a decline in supply in the winter months (July-September).
\end{abstract}

Index terms: Apis mellifera, apiculture, flowering time, honeybee flora, botanic inventory, meliponiculture.

\section{Introdução}

A apicultura e a meliponicultura são atividades produtivas que podem ser desenvolvidas simultaneamente com outras atividades, e que contribuem para aumentar a viabilidade econômica das propriedades rurais no Pantanal (Reis \& Comastri Filho, 2003). Para o desenvolvimento da apicultura e da meliponicultura numa região, é necessário que se conheça a flora melífera, bem como os recursos florais disponíveis para as abelhas, que variam em função do bioma, das estações do ano e dos anos avaliados. Portanto, o conhecimento da flora melífera regional é um passo importante para conservar e explorar racionalmente as abelhas, uma vez que facilita operações de manejo do apiário ou meliponário, 
e possibilita identificar, preservar e multiplicar as espécies vegetais mais importantes na área (Wiese, 1995).

Os levantamentos sobre a flora melífera com avaliação da disponibilidade e da época de floração das plantas são geralmente realizados pela observação direta da planta visitada pelas abelhas nativas ou africanizadas (Carvalho \& Marchini, 1999; Marchini et al., 2001; Moreti et al., 2006; Pinheiro et al., 2008; Vieira et al., 2008), ou pela observação indireta por meio da análise do pólen apícola (Mendonça et al., 2008) e dos grãos de pólen presentes no mel (Mendonça et al., 2008; Sodré et al., 2008) ou na própolis (Santos et al., 2003).

As informações disponíveis sobre a flora melífera no Brasil ainda são empíricas e restritas a algumas regiões do País. A maioria dos trabalhos publicados foi realizada nas regiões Sul (Pinheiro et al., 2008; Sekine et al., 2013), Sudeste (Marchini et al., 2001; Mendonça et al., 2008) e Nordeste (Carvalho \& Marchini, 1999; Sodré et al., 2008). Essas três regiões também são as que apresentam maior produção de mel no Brasil, que, em 2013, foi de 35.365 toneladas: a região Sul contribuiu com 50,2\%, a Sudeste com $21,5 \%$ e a Nordeste com 21,3\% (Produção Pecuária Municipal, 2013). A região Centro-Oeste é uma das que menos produz mel no País, com participação de apenas $4,4 \%$ na produção nacional (Produção Pecuária Municipal, 2013), apesar da rica flora nativa encontrada principalmente nos biomas Cerrado e Pantanal.

Há pouca informação organizada disponível sobre a florada de plantas melíferas na região Centro-Oeste, como as obtidas por Schleder et al. (2007), em uma fazenda em Campo Grande, MS; Moreti et al. (2006) e Vieira et al. (2008), em áreas de Cerrado em Cassilândia, MS; e Soares et al. (2007), nos municípios de Cáceres, Conquista D'Oeste e Pontes e Lacerda, MT. Já para o Pantanal, foram registradas 162 espécies apícolas por Pott \& Pott (1986); 386 espécies melíferas, em compilação de dados de herbários e da literatura por Salis et al. (2009); e 63 plantas - bem como os recursos coletados pelas abelhas - em levantamento por Boff et al. (2013).

O objetivo deste trabalho foi avaliar o padrão de floração, ao longo do ano, de plantas melíferas na Borda Oeste do Pantanal, no Maciço do Urucum, MS, bem como o tipo de recurso oferecido pela flora melífera, para elaborar um calendário floral para a região.

\section{Material e Métodos}

O estudo foi realizado na fazenda Band'Alta $\left(19^{\circ} 08^{\prime} 34,6^{\prime \prime} \mathrm{S}, \quad 57^{\circ} 35^{\prime} 12,1^{\prime \prime} \mathrm{W}\right)$, que pertence ao Colégio Salesiano de Santa Teresa, no Município de Ladário, MS, ao sopé de um morro integrante do Maciço do Urucum, na Borda Oeste do Pantanal. Essa região apresenta clima Awa, segundo a classificação de Köppen, ou seja, clima tropical megatérmico (Soriano, 1997), com inverno seco e chuvas no verão, e precipitação média anual de $1.070 \mathrm{~mm}$, com média anual da temperatura mínima de $21^{\circ} \mathrm{C}$ e da temperatura máxima de $31^{\circ} \mathrm{C}$. Dados de precipitação foram obtidos da estação meteorológica (Estação São Simão) mais próxima da área da fazenda (Agência Nacional de Águas, 2014), e os de temperaturas máxima e mínima do ar, da área do Aeroporto Internacional de Corumbá (Instituto Nacional de Pesquisas Espaciais, 2014).

Três trilhas, distantes no máximo $1,5 \mathrm{~km}$ dos dois apiários (na baixada e no morro), foram percorridas quinzenalmente, no período de março de 2006 a março de 2009. Os apiários estavam cerca de $600 \mathrm{~m}$ distantes entre si. As trilhas abrangiam diferentes fisionomias da fazenda Band'Alta: pastagem cultivada com braquiária, bem como árvores esparsas remanescentes da vegetação original, e ervas e arbustos ruderais; margem de córrego com muitas mangueiras, árvores remanescentes da mata ciliar e campo inundável e, na base do morro, remanescente de floresta semidecídua. A coleta de dados foi realizada das $8 \mathrm{~h} 00$ às $11 \mathrm{~h} 00$, o que totalizou cerca de 200 horas de esforço amostral. Flores visitadas por abelhas nativas (jataí, mamangava, saranhão e outras) e africanizadas tiveram seu hábito de crescimento registrado como erva (incluiu subarbustos menores que 1,0 $\mathrm{m}$ de altura), arbusto, árvore ou liana. Além disso, o recurso floral ou extrafloral coletado pelas abelhas (pólen, néctar e resina) também foi registrado.

As plantas floridas foram classificadas de 1 a 4, quanto à intensidade da floração (Fournier, 1974), tendo-se avaliado a quantidade de flores por espécie e o número de indivíduos floridos na área, da seguinte forma: 1, presença de floração com intensidade de 1 a $25 \%$, ou pouco florida; 2 , presença de floração com intensidade entre 26 e $50 \%$, ou medianamente florida; 3 , presença de floração com intensidade entre 51 e $75 \%$, ou muito florida; e 4 , presença de floração com intensidade entre 76 e $100 \%$, ou abundantemente florida. Amostras botânicas foram coletadas de todas 
as espécies, para confirmação da identificação e posterior incorporação ao acervo do Herbário CPAP, da Embrapa Pantanal. Essas amostras foram identificadas por consulta à literatura técnica e a especialistas, e por meio da comparação com material do Herbário CPAP.

Para a inclusão das espécies no calendário floral, utilizou-se a definição de planta melífera de Castro (1994), que considera como tal aquelas que ocorrem em abundância na área estudada, florescem copiosamente e que possuem néctar ou pólen acessível para as abelhas. Assim, foram incluídas todas as plantas que tenham atingido intensidade de floração igual ou superior a 3 em pelo menos 1 mês, nos 3 anos de acompanhamento.

\section{Resultados e Discussão}

Foram identificadas 160 espécies de plantas visitadas por abelhas nativas ou africanizadas, no sopé do Maciço do Urucum. Dessas, foram consideradas melíferas e incluídas no calendário floral 73 espécies, sendo 34 ervas, 17 árvores, 15 arbustos e 7 lianas, distribuídas em 59 gêneros e 28 famílias (Tabela 1). A maioria dessas espécies (89\%) é nativa da região, e somente $11 \%$ são cultivadas ou naturalizadas, de acordo com a Lista de Espécies da Flora do Brasil (Lista..., 2015).

As famílias botânicas que mais se destacaram em número de espécies melíferas foram: Fabaceae, com 20 espécies; Malvaceae, com 9; e Euphorbiaceae, com 4. Estudos nos biomas Caatinga (Carvalho \& Marchini, 1999) e Cerrado (Vieira et al., 2008) também indicaram Fabaceae e Malvaceae como importantes famílias melíferas.

As principais plantas apícolas observadas na Borda Oeste do Pantanal foram classificadas como ervas (47\% das espécies), resultado semelhante ao relatado por Santos et al. (2006) em área de Caatinga (41\% de ervas). A maioria dessas ervas, comumente consideradas como invasoras (Brandão et al., 1985), ocorreu em áreas degradadas da pastagem de braquiária (Tabela 1). Várias delas, como Commelina erecta L., Corchorus hirtus L., Gomphrena celosioides Mart., Hyptis suaveolens (L.) Poit., Indigofera hirsuta L., Malvastrum coromandelianum (L.) Garcke, Senna occidentalis (L.) Link (syn.: Cassia occidentalis), Sida rhombifolia L. e Wissadula hernandioides Garcke (syn.: Wissadula subpeltata), foram mencionadas como bom pasto apícola em diferentes estudos (Marchini et al., 2001; Almeida et al., 2003; Schleder et al., 2007; Silva et al., 2008; Novais \& Navarro, 2012; Sekine et al., 2013), realizados em várias regiões do Brasil. As espécies herbáceas floresceram principalmente durante o verão e o outono (janeiro a junho), no período mais chuvoso (Figura 1), resultado similar ao relatado por Pott \& Pott (1986) e Salis et al. (2009), na planície pantaneira, e por Carvalho \& Marchini (1999) e Santos et al. (2006), em áreas de Caatinga na Bahia e em Pernambuco, respectivamente. As lianas, 10\% das espécies, floresceram mais no final do verão (março e abril).

As árvores e os arbustos melíferos ocorreram com 17 e 15 espécies, 23 e $20 \%$ respectivamente, e floresceram principalmente no final do inverno e na primavera (setembro a dezembro), semelhantemente ao observado por Lusardi et al. (2001) em Rosário, na Argentina. A exceção ocorreu em 2007, com queda de floração dos arbustos em setembro e outubro, provavelmente relacionada à ausência de precipitação em setembro (Figura 1). Ou seja, as árvores e os arbustos geralmente floresceram quando poucas ervas estavam em flor, e, portanto, constituíram importantes fontes de recursos para as abelhas nativas e africanizadas nesse período de menor oferta de recursos. Contudo, como as árvores e os arbustos ocorreram em menor número, há de se observar se esses recursos são suficientes para a manutenção de colônias de abelhas nativas ou africanizadas em condições produtivas.

Quanto aos recursos oferecidos pelas plantas melíferas, $42 \%$ das espécies ofereceram somente néctar; $22 \%$, somente pólen; $32 \%$ ofereceram dois recursos (néctar, pólen ou resina); e somente $4 \%$ ofereceram pólen, néctar e resina. Esses resultados são similares aos obtidos por Pinheiro et al. (2008), em uma formação campestre no Parque Estadual de Itapuã, RS, com precipitação anual entre 1.100 e $1.300 \mathrm{~mm}$, em que $41,5 \%$ das espécies vegetais ofereceram néctar; 21,6\%, pólen; e 27,3\%, néctar e pólen. No entanto, Nunes et al. (1996), em área de Caatinga de Mossoró, RN, e Merti (2003), em fazenda em Grahamstown, na África do Sul, relataram proporções opostas, em que $26 \%$ das plantas ofereceram néctar, e 43,5\% (Mossoró) e 66\% (Grahamstown), pólen. Merti (2003) atribuiu o maior número de plantas que disponibilizaram pólen em Grahamstown à umidade restrita na região da fazenda, onde a precipitação média anual é de $613 \mathrm{~mm}$, similar 


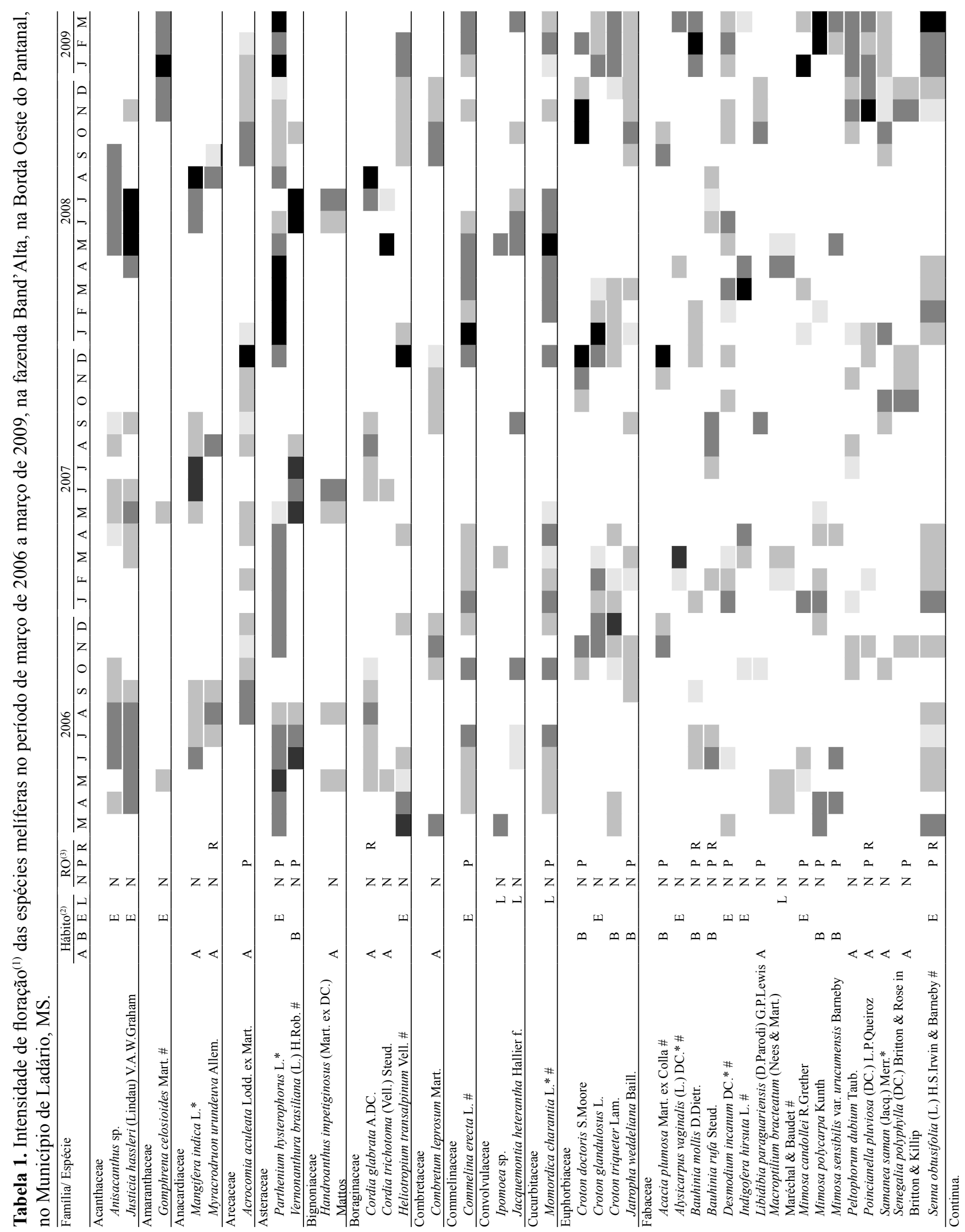




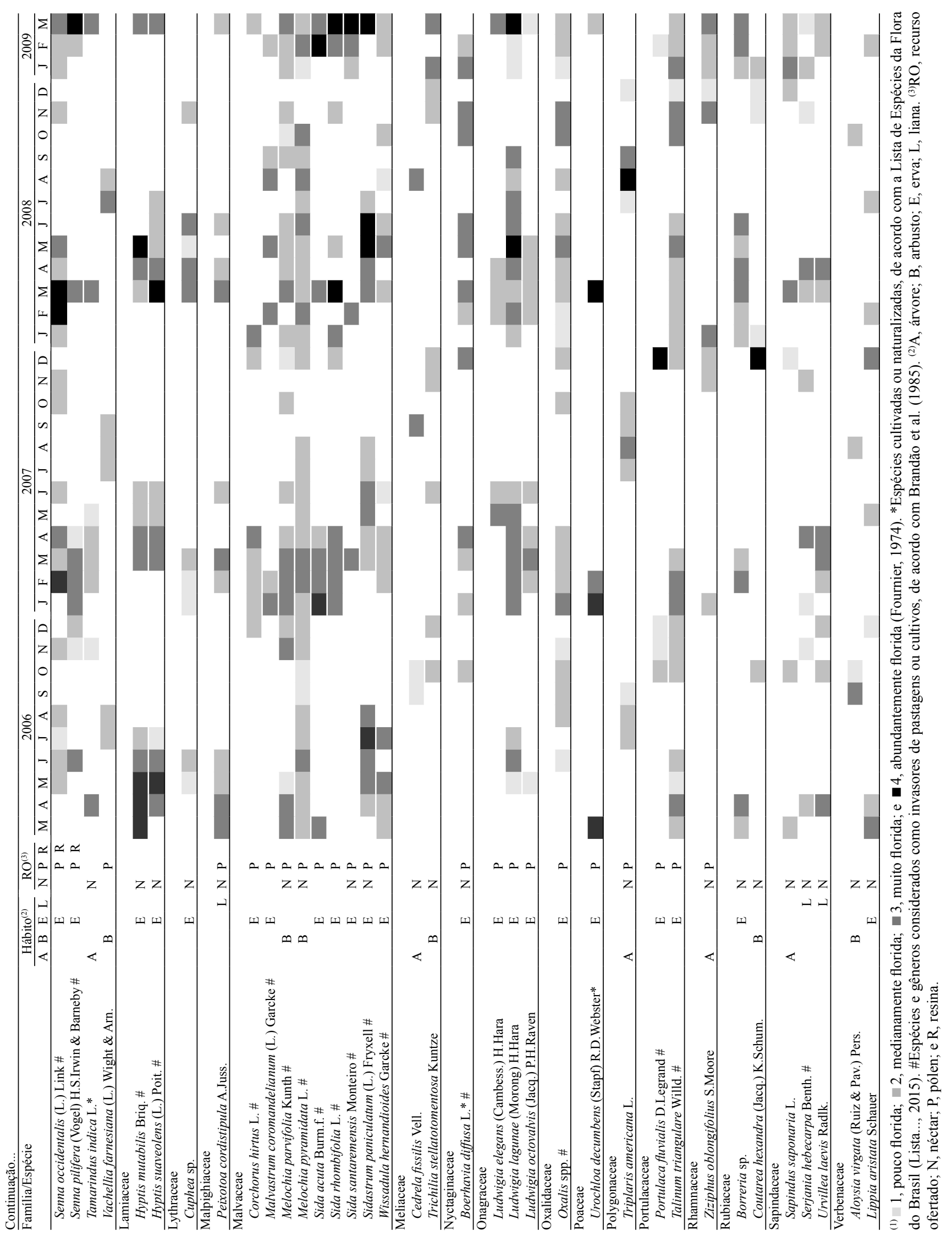


aos $676 \mathrm{~mm}$ registrados em Mossoró por Nunes et al. (1996). Isso pode explicar o maior número de plantas que ofereceram néctar na Borda Oeste do Pantanal, pois esta apresenta precipitação média anual de $1.070 \mathrm{~mm}$ (Soriano, 1997).

Em relação à disponibilidade de recursos florais e extraflorais totais (Figura 2), observou-se menor número de espécies que ofertaram pólen e néctar no inverno (julho a setembro), e maior oferta de ambos no verão (janeiro a março). Entre 10 e 15 espécies de ervas ofertaram néctar ou pólen principalmente nos meses de verão, que são os mais chuvosos na região. As lianas, como as ervas, também floresceram no verão e no início do outono; porém, ofertaram mais néctar. Os arbustos ofertaram tanto néctar quanto pólen ao longo de todo o ano, com pico na primavera. As árvores começaram a ofertar mais néctar, a partir do inverno, com pico também na primavera. Portanto, plantas com esses diferentes hábitos de crescimento ofertaram, de forma complementar, recursos ao longo do ano. Entretanto, deve-se observar que, especialmente nos meses de inverno - mesmo com a florada mais intensa das árvores - ocorre diminuição acentuada no número total de espécies floridas, de cerca de 20 para 10 , ou menos, o que pode limitar a disponibilidade de recursos para que as colônias de abelhas nativas e africanizadas se desenvolvam adequadamente. Dessa forma, nesse período de menor oferta, é importante que o apicultor ou o meliponicultor acompanhe o nível de desenvolvimento das colmeias.
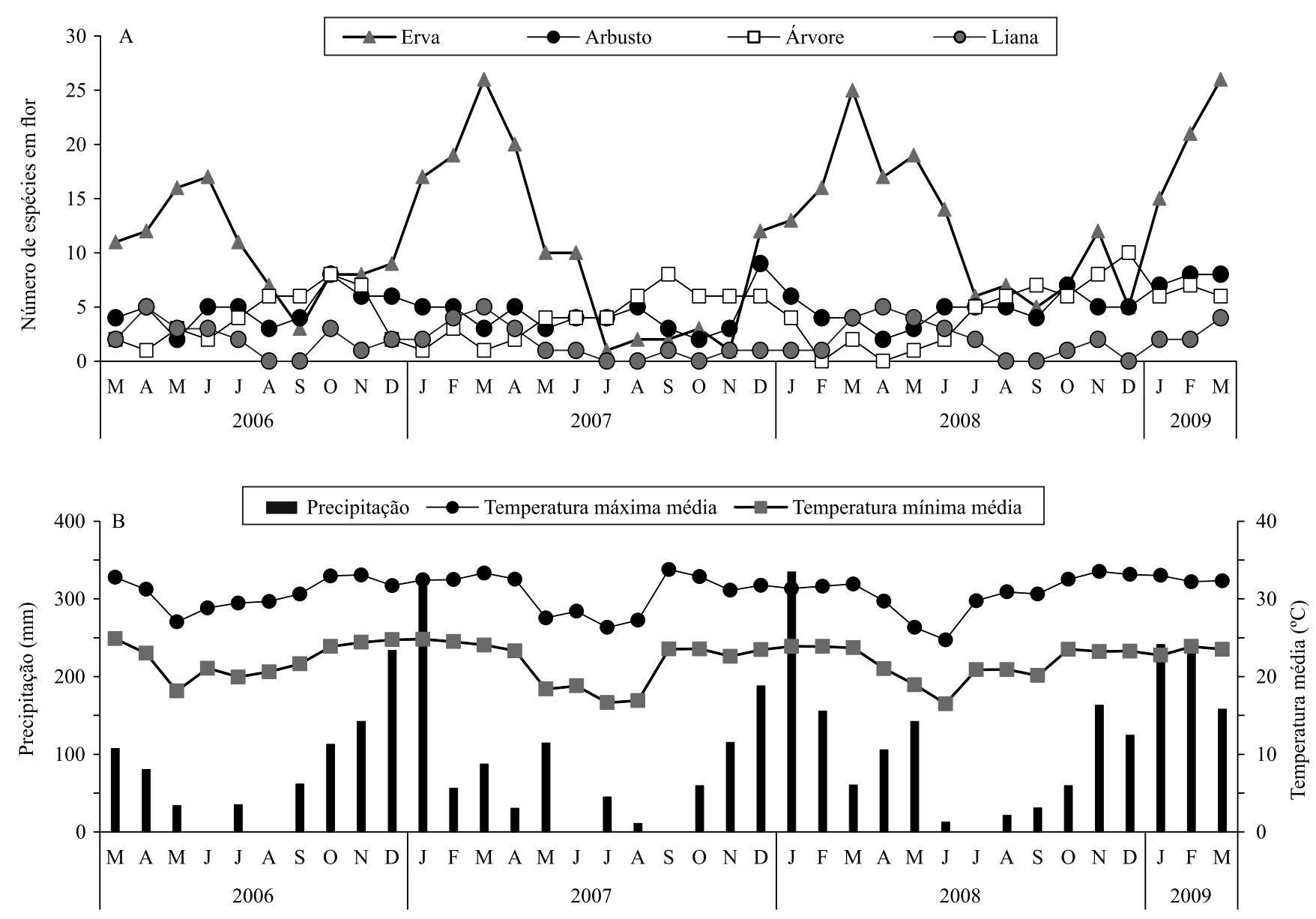

Figura 1. Espécies floridas por hábito de crescimento no período de março de 2006 a março de 2009, na fazenda Band'Alta, em Ladário, MS (A); e dados de precipitação da Estação São Simão (Agência Nacional de Águas, 2014) e de temperaturas médias máximas e mínimas registradas no Aeroporto Internacional de Corumbá (Instituto Nacional de Pesquisas Espaciais, 2014), no Município de Corumbá, MS (B). 

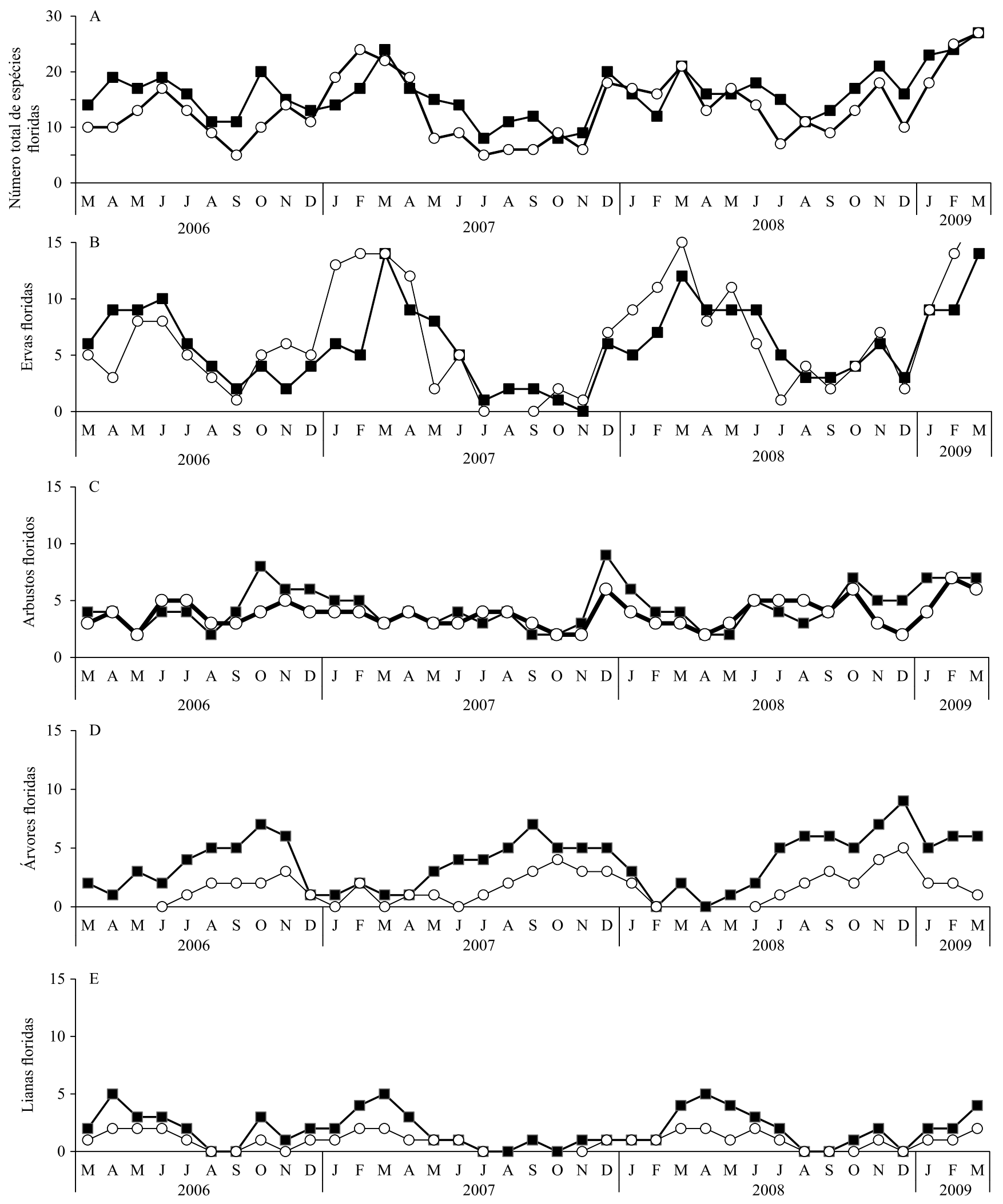

$\rightarrow$-Néctar $\multimap$-Pólen

Figura 2. Néctar e pólen disponibilizados pelas plantas melíferas, no período de março de 2006 a março de 2009: A, total; B, $\mathrm{C}, \mathrm{D}$ e E, de acordo com hábito de crescimento. 
Algumas árvores de espécies nativas - como Cedrela fissilis Vell., Combretum leprosum Mart., Cordia trichotoma (Vell.) Steud., Myracrodruon urundeuva Allem. (syn.: Astronium urundeuva), Senegalia polyphylla (DC.) Britton \& Rose in Britton \& Killip (syn.: Acacia polyphyla) e Handroanthus impetiginosus (Mart. ex DC.) Mattos (syn.: Tabebuia impetiginosa) - e de cultivadas - como Mangifera indica L. e Tamarindus indica L. - consistiram em importantes fontes de recursos para as abelhas na Borda Oeste do Pantanal. Essas espécies também foram relatadas como importantes para esse fim por outros autores (Almeida et al., 2003; Nunes et al., 1996; Moreti et al., 2006; Silva et al., 2008; Vieira et al., 2008; Novais \& Navarro, 2012; Sekine et al., 2013), em diferentes regiões do País. Em razão de sua importância melífera, essas árvores devem ser conservadas e ter a sua frequência aumentada na região.

As temperaturas mínimas médias mensais observadas no aeroporto de Corumbá, durante os 3 anos de estudo, ficaram sempre acima de $14^{\circ} \mathrm{C}$ (Figura 1), com ocorrência de temperaturas absolutas abaixo desse valor em apenas 4 dias, em 2006; 28 dias, em 2007; e 14 dias, em 2008. As temperaturas máximas médias mensais ficaram em torno de 25 e $34^{\circ} \mathrm{C}$, com ocorrência de valores absolutos acima de $34^{\circ} \mathrm{C}$, nos meses de primavera e de verão, em: 23 dias, em 2006; 44 dias, em 2007; 35 dias, em 2008; e 18 dias, em 2009. Segundo Almeida et al. (2003), temperaturas do ar elevadas, entre 25 e $32^{\circ} \mathrm{C}$, são ideais para a produção de néctar pelas plantas, porque tornam a membrana dos nectários mais permeável, o que aumenta o poder solvente da água e acelera as reações químicas nas plantas. Isso significa que, na Borda Oeste do Pantanal, praticamente não ocorre limitação de temperatura durante o ano para que as plantas produzam néctar e, também, para que as abelhas africanizadas coletem pólen, uma vez que, conforme Merti (2003), a temperatura ótima para Apis melifera coletar pólen é acima de $14^{\circ} \mathrm{C}$.

As informações obtidas no presente trabalho indicam que a região da Borda Oeste do Pantanal reúne condições favoráveis para o desenvolvimento da apicultura e da meliponicultura, pois apresenta flora polinífera e nectarífera com florescimento ao longo de todo o ano, bem como clima sem inverno longo, com ocorrência de poucos dias com baixas temperaturas e com índice pluvial moderado.

\section{Conclusões}

1. As espécies melíferas avaliadas na região do Maciço do Urucum, na Borda Oeste do Pantanal, florescem ao longo de todo o ano, com maior número de espécies no verão (janeiro a março), e menor, no inverno (julho a setembro).

2. A interação entre o hábito de crescimento das plantas melíferas e o clima influencia a época de floração, e faz com que ervas e lianas floresçam principalmente no verão e no outono (janeiro a junho), e as árvores e arbustos, na primavera (final de setembro a dezembro).

3. Há disponibilidade de néctar e de pólen ao longo de todo o ano, com diminuição da oferta nos meses de inverno (julho a setembro).

\section{Agradecimentos}

À Fundação de Apoio ao Desenvolvimento do Ensino, Ciência e Tecnologia do Estado de Mato Grosso do Sul (Fundect), e ao Conselho Nacional de Desenvolvimento Científico e Tecnológico (CNPq), pelo apoio financeiro e pela concessão de bolsas; às botânicas Maria Beatriz Rossi Caruso e Rosilene Rodrigues Silva, pela identificação de espécies das famílias Euphorbiaceae e Fabaceae; aos estagiários Damião Teixeira de Azevedo, Elinaldo Gomes de Oliveira, Helena Cespedes Garcia, José Edmo Pereira Junior, Thaisa Aparecida Campagna de Assis, Wendy Judy Padilla Castro, e aos colegas da Embrapa Pantanal, Gentil Cavalcante Brasil Sobrinho (in memoriam), Oslain Domingos Branco, Sebastião de Jesus, Marcos Tadeu Borges Daniel Araújo, Ayrton de Araújo, Denis Celin Tilcara, Haroldo Lara Cunha, Moacir Ortiz de Assis, Wilson dos Santos Batista, Antonio Arantes Bueno Sobrinho e Fernando Carlos Bardauil, pelo auxílio no preparo do material para campo, nas coletas de campo e na organização do material no herbário; à pesquisadora Cátia Urbanetz, pelas sugestões feitas no abstract; e ao mestre Altair Gonçalo Monteiro da Silva, por permitir a realização do experimento na Fazenda Band'Alta.

\section{Referências}

AGÊNCIA NACIONAL DE ÁGUAS (Brasil). Sistema Nacional de Informações sobre Recursos Hídricos. Banco de Dados Hidrometeorológicos. Chuvas - médias mensais - Estação São Simão. Disponível em: <http://www.ana.gov.br/PortalSuporte/ 
frmDadosEstacao.aspx ?estacao $=2057001 \&$ tipo $=$ Chuvas $>$. Acesso em: 26 jul. 2014.

ALMEIDA, D. de; MARCHINI, L.C.; SODRÉ, G. da S.; D'ÁVILA, M.; ARRUDA, C.M.F. de. Plantas visitadas por abelhas e polinização. Piracicaba: USP/Esalq, 2003. 40p. (Série Produtor Rural, Edição Especial).

BOFF, S.; ARAUJO, A.C.; POTT, A. Bees (Hymenoptera: Apoidea) and flowers of natural forest patches of southern Pantanal. Biota Neotropica, v.13, p.46-56, 2013. DOI: 10.1590/ S1676-06032013000400005.

BRANDÃO, M.; LACA-BUENDIA, J.P.; GAVILANES, M.L.; ZURLO, M.A.; CUNHA, L.H. de S.; CARDOSO, C. Novos enfoques para plantas consideradas daninhas. Informe Agropecuário, v.11, p.3-12, 1985.

CARVALHO, C.A.L. de; MARCHINI, L.C. Plantas visitadas por Apis mellifera L. no vale do rio Paraguaçu, Município de Castro Alves, Bahia. Revista Brasileira de Botânica, v.22, p.333-338, 1999. DOI: 10.1590/S0100-84041999000500016.

CASTRO, M.S. de. Plantas apícolas: identificação e caracterização. In: BRANDÃO, A.L.S.; BOARETTO, M.A.C. (Ed.). Apicultura atual: diversificação de produtos. Vitória da Conquista: UESB, 1994. p.21-31.

FOURNIER, L.A. Un método cuantitativo para la medición de características fenológicas en árboles. Turrialba, v.24, p.422-423, 1974.

INSTITUTO NACIONAL DE PESQUISAS ESPACIAIS (Brasil). Centro de Previsão de Tempo e Estudos Climáticos. Banco de Dados Meteorológicos. Disponível em: <http://bancodedados. cptec.inpe.br/ downloadBDM/>. Acesso em: 26 ago. 2014.

LISTA de espécies da flora do Brasil. Rio de Janeiro: Instituto de Pesquisas Jardim Botânico. Disponível em: <http://floradobrasil. jbrj.gov.br/>. Acesso em: 25 jan. 2015.

LUSARDI, M.; SCANDIZZI, A.; MCCARGO, J.; GATTUSO, M.; GATTUSO, S.; ARDUSSO, L.; CRISCI, C. Calendario de floración de especies frecuentes en la ciudad de Rosario (Santa Fe), Argentina. Archivos de Alergia e Inmunología Clínica, v.32, p.93-97, 2001.

MARCHINI, L.C.; MORETI, A.C. de C.C.; TEIXEIRA, E.W.; SILVA, E.C.A. da; SOUZA, V.C. Plantas visitadas por abelhas africanizadas em duas localidades do Estado de São Paulo. Scientia Agrícola, v.58, p.413-420, 2001. DOI: 10.1590/ S0103-90162001000200028.

MENDONÇA, K.; MARCHINI, L.C.; SOUZA, B. de A.; ALMEIDA-ANACLETO, D. de; MORETI, A.C. de C.C. Plantas apícolas de importância para Apis mellifera L. (Hymenoptera: Apidae) em fragmento de cerrado em Itirapina, SP. Neotropical Entomology, v.37, p.513-521, 2008. DOI: 10.1590/ S1519-566X2008000500003.

MERTI, A.A. Botanical inventory and phenology in relation to foraging behaviour of the cape honeybees (Apis mellifera capensis) at a site in the Eastern Cape, South Africa. 2003. 156p. Thesis (Master of Science) - Rhodes University, Grahamstown.
MORETI, A.C. de C.C.; ANACLETO, D. de A.; D'AVILA, M.; VIEIRA, G.H. da C.; MARCHINI, L.C. Abelhas visitantes em vegetação de diferentes áreas remanescentes de cerrado. Magistra, v.18, p.229-248, 2006.

NOVAIS, J.S. de; NAVARRO, E.D.M. A flowering calendar of plants growing near hives of native bees in the lower Amazon region, Pará State, Brazil. Uludag Bee Journal, v.12, p.83-88, 2012.

NUNES, C.G.F.; MATOS, R.R.; OLIVEIRA, O.F. de; BEZERRA NETO, F. Identificação de plantas apícolas no campus da Esam, Mossoró, RN. Caatinga, v.9, p.91-96, 1996.

PINHEIRO, M.; ABRÃO, B.E. de; HARTER-MARQUES, B.; MIOTTO, S.T.S. Floral resources used by insects in a grassland community in southern Brazil. Revista Brasileira de Botânica, v.31, p.469-489, 2008. DOI: 10.1590/ S0100-84042008000300011.

POTT, A.; POTT, V.J. Inventário da flora apícola do Pantanal em Mato Grosso do Sul. Corumbá: EMBRAPA-CPAP, 1986. 16p. (EMBRAPA-CPAP. Pesquisa em andamento, 3).

PRODUÇÃO DA PECUÁRIA MUNICIPAL. Rio de Janeiro: IBGE, v.41, 2013, 108p. Disponível em: <http://biblioteca.ibge. gov.br/visualizacao/periodicos/84/ppm_2013_v41_br.pdf $>$. Acesso em: 10 jul. 2015.

REIS, V.D.A. dos; COMASTRI FILHO, J.A. Importância da apicultura no Pantanal Sul-Mato-Grossense. Corumbá: Embrapa Pantanal, 2003. 23p. (Embrapa Pantanal. Documentos, 56).

SALIS, S.M. de; REIS, V.D.A. dos; MARCONDES, A.N. Floração de espécies apícolas no Pantanal baseada em informações de herbário e literatura. Corumbá: Embrapa Pantanal, 2009. 47p. (Embrapa Pantanal. Boletim de pesquisa e desenvolvimento, 91).

SANTOS, F.A.; BASTOS, E.M.A.F.; MAIA, A.B.R.A.; UZEDA, M.; CARVALHO, M.A.R.; FARIAS, L.M.; MOREIRA, E.S.A. Brazilian propolis: physicochemical properties, plant origin and antibacterial activity on periodontopathogens. Phytotherapy Research, v.17, p.285-289, 2003. DOI: 10.1002/ptr.1117.

SANTOS, R.F.; KIILL, L.H.P.; ARAÚJO, J.L.P. Levantamento da flora melífera de interesse apícola no Município de Petrolina-PE. Revista Caatinga, v.19, p.211-227, 2006.

SCHLEDER, E.J.D.; BUENO, M.L.; SILVÉRIO, V. de L.; AQUINO, G.N.R. de; RIVABEN, R.C. Levantamento da diversidade da flora apícola na Fazenda Escola Três Barras/ UNIDERP, Campo Grande, Mato Grosso do Sul. Revista Brasileira de Biociências, v.5, p.375-377, 2007.

SEKINE, E.S.; TOLEDO, V.A.A.; CAXAMBU, M.G.; CHMURA, S.; TAKASHIBA, E.H.; SEREIA, M.J.; MARCHINI, L.C.; MORETI, A.C.C.C. Melliferous flora and pollen characterization of honey samples of Apis mellifera L., 1758 in apiaries in the counties of Ubiratã and Nova Aurora, PR. Anais da Academia Brasileira de Ciências, v.85, p.307-326, 2013. DOI: 10.1590/ S0001-37652013005000017.

SILVA, R.A. da; EVANGELISTA-RODRIGUES, A.; AQUINO, I. de S.; FELIX, L.P.; MATA, M.F.; PERONICO, A.S. Caracterização da flora apícola do semi-árido da Paraíba. Archivos de Zootecnia, v.57, p.427-438, 2008. 
SOARES, E.R. de C.; PESTANA, D.D.; BARELLI, M.A.A.; GALBIATI, C.; AMARAL, A.M. do; SILVA, E.R.G.; FAVARE, L.G. de; BISLER, J.P.; PEREIRA, R.P.; ANTENOR, F.L. Seleção de espécies melíferas com base na flora da região Sudoeste do Estado de Mato Grosso. Revista Brasileira de Biociências, v.5, p.726-728, 2007.

SODRÉ, G. da S.; MARCHINI, L.C.; MORETI, A.C. de C.C.; CARVALHO, C.A.L. de. Tipos polínicos encontrados em amostras de méis de Apis mellifera em Picos, Estado do Piauí. Ciência Rural, v.38, p.839-842, 2008. DOI: 10.1590/ S0103-84782008000300043.
SORIANO, B.M.A. Caracterização climática de Corumbá-MS. Corumbá: EMBRAPA-CPAP, 1997. 25p. (EMBRAPA-CPAP. Boletim de pesquisa, 11).

VIEIRA, G.H.da C.; MARCHINI, L.C.; SOUZA, B. deA.; MORETI, A.C. de C.C. Fontes florais usadas por abelhas (Hymenoptera, Apoidea) em área de cerrado no Município de Cassilândia, Mato Grosso do Sul, Brasil. Ciência e Agrotecnologia, v.32, p.1454-1460, 2008. DOI: 10.1590/S1413-70542008000500015.

WIESE, H. Novo manual de apicultura. Guaíba: Agropecuária, 1995. 292p.

Recebido em $1^{\circ}$ de abril de 2015 e aprovado em 22 de julho de 2015 